\title{
Thiophenes of Tagetes Flowers and Partial Purification of Xanthophyll Esters
}

\author{
Victor I. Deineka ${ }^{1}$, Michael Yu. Tret'yakov ${ }^{2}$, Maria S. Lapshova ${ }^{1}$, Ludmila A. Deineka ${ }^{1, *}$ \\ ${ }^{1}$ National Research University "Belgorod State University”, Belgorod, 308015, Pobeda str. 85, Russian Federation \\ ${ }^{2}$ Belgorod State Research Institute of Agriculture, Russian Academy of Agricultural, 308001, Belgorod, October Str., 58 \\ *Corresponding Author: deineka@bsu.edu.ru
}

Copyright $@ 2014$ Horizon Research Publishing All rights reserved.

\begin{abstract}
Lutein is a health promoting xanthophyll that may be extracted from marigold flowers. But the plant is known also for biosynthesis of phototoxic polythiophenes. Extracts of flowers of some Tagetes species grown in Belgorod (RF) T. erecta L. (cv. Gavaii), T. patula L. (cv. Petit orange), T. tenuifolia Cav. (unknown cv.), and T. lucida Cav. were investigated by thin layer chromatography (TLC) and high-performance chromatography (HPLC) with diode-array (DAD) and mass spectomertic detector (MS). It has been found that $\mathrm{C}_{13}$ bithienyl (instead of $\mathrm{C}_{12}$-derivatives being common for hairy roots) was a major thiophene derivative of all extracts under investigation, and that thiophenes are accumulated mainly in the parts of flowers hidden from sunlight by a flower's sepals. Therefore two methods of petal preparation for lutein diesters extraction were investigated. It has been shown that solid phase extraction on silica is a simple way for lutein diesters purification from thiophenes.
\end{abstract}

Keywords Tagetes Species, Thiophenes, Xanthophylls, TLC, HPLC, SPE (Solid Phase Extraction)

\section{Introduction}

Tagetes sp. (Compositae) are well known not only as ornamental plants but also for their ability to accumulate lutein esters in flowers sepals [1]. That is why the plants are the major commercial source of lutein, growing up worldwide. A level of xanthophyll's accumulation tightly correlates with a color of flowers being the highest for dark-orange petals [1, 2]. It should be also noticed that English trivial name of the plant genus: (African) marigold $T$. erecta, (French) marigold $-T$. patula etc. led to a duplicated mess in commercial because of a similar name of Calendula sp. - (pot) marigold. An information about calendula as a source of lutein is entirely wrong for this plant's flowers carotenoids are of another structures for all known varieties [3].

The type of lutein acylation was under investigation in some papers mainly by means of the reversed-phased HPLC [4] especially with mass-spectroscopic detection $[5,6]$. The lutein esters were found to be formed by only saturated fatty acids from lauric to stearic with a predominant role of palmitic and myristic acids. Petal's xanthophyll complex may include lutein, monoesters as well as diesters of lutein, while the degree of esterification determines the overall xanthophyll accumulation [2].

For the esters are synthesized together with a lot of other substances the purification of crude extract of flowers petals is not only desired but rather necessary. An ordinary route to get a pure lutein involves lutein esters extraction, saponification and finally lutein crystallization [7]. Meanwhile it is known that esterification does not impair lutein bioavailability in humans [8], so the saponification may be excluded provided a proper purification of lutein esters is performed.

Among the possible impurities of the extract the phototoxic thiophenes are the specific compounds of the genus. Though series of thiophenes accumulates predominately in hairy roots [9], it was shown that they are synthesized in all parts of the plant [10]. Meanwhile results of our investigations of petal's extracts were rather surprising showing the presence of thiophenes in some cases and the absence in the others.

The aim of the present investigation was to determine the reason of appearance or disappearing of the thiophenes in Tagetes petals extracts and to develop a simple method for the thiophenes detection and separation from the xanthophyll esters.

\section{Materials and Methods}

\subsection{Plant Material}

Tagetes erecta L. (cv. Gavaii), T. patula L. (cv. Petit orange), T. tenuifolia Cav. (unknown cv.), and T. lucida Cav. were grown in 2012 and in 2013 in Belgorod, RF. All the flowers under investigation were cut off at midday, brought to laboratory and left for drying in places without direct 
sunlight illumination otherwise the extracts were made within 2 hours.

\subsection{Plant Material Preparation}

Two methods were used to prepare marigold flowers before drying or extraction. The first method (A) implied removing of ray florets from the capitulum, while in the second way (B) we cut only the parts of the florets (petals) that were not covered in capitulum (Figure 1).

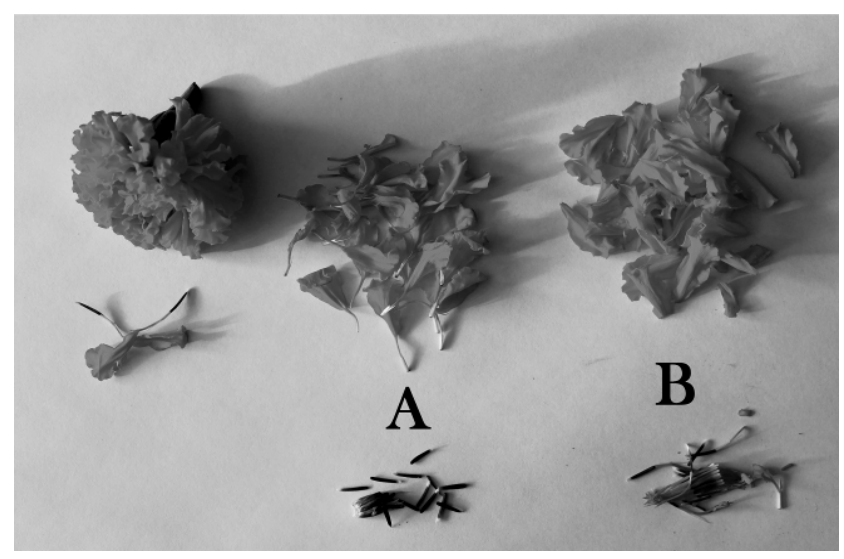

Figure 1. Two types of petals preparation

\subsection{Extraction and Preparation for Chromatographic Investigations}

The fresh flowers $(0.2 \mathrm{~g})$ were extracted exhaustively with 3 - 4 portions of $5 \mathrm{ml}$ of hexane by grinding of plant material in ceramic mortar with anhydrous $\mathrm{Na}_{2} \mathrm{SO}_{4}$ under hexane layer at reduced illumination. Dried petals were extracted by the same way except of the preliminary wetting with water for $5 \mathrm{~min}$.

All the extract portions were collected in a flask by filtration through paper filter; concentrated in vacuum rotary evaporator; the final extract volume being made up by hexane in $5 \mathrm{ml}$ volumetric flask for TCL or by eluent for HPLC and filtered through PTFE-B membranes of MS ${ }^{\circledR}$ Syringe Filters with 0.455 pore size.

\subsection{Partial Extract Purification}

For partial purification the concentrated extract (2.3) was passed through DIAPAC cartridge (BioChemMack ST, Moscow, RF) filled with $\mathrm{SiO}_{2}$. The eluate (E) with unretained substances was collected. The xanthophylls from the cartridge were eluted by acetone - eluate $(\mathbf{S})$.

For preparing samples for TLC investigation $5 \mathrm{ml}$ of $\mathbf{S}$ were placed in a separatory flask, $5 \mathrm{ml}$ of hexane and $20 \mathrm{ml}$ of saturated $\mathrm{NaCl}$ solution in distilled water were added and the flask was shaken vigorously for $30 \mathrm{~s}$. After layers' separation the water phase was withdrawn and the hexane solution was twice washed from acetone by the same portions of $\mathrm{NaCl}$ solution. Finally the hexane solution was dried under anhydrous $\mathrm{Na}_{2} \mathrm{SO}_{4}$ before applying to
TLC-plates.

\subsection{Thin Layer Chromatography}

The TLC separation was performed in chromatographic chambers presaturated with eluent for $20 \mathrm{~min}$. Silica plates $(10 \times 10 \mathrm{~cm}$ aluminium sheets, Sorbfil. RF) without any preparations were used. Eluent was composed of acetone and hexane (pure for analysis grade, EKOS, RF).

After evaporation of eluent the plates were monitored in UV Cabinet under long-wave UV light $366 \mathrm{~nm}$. The pictures have been photographed by the camera, Figure 2. The thiophenes are detected as a bright blue fluorescent spots.

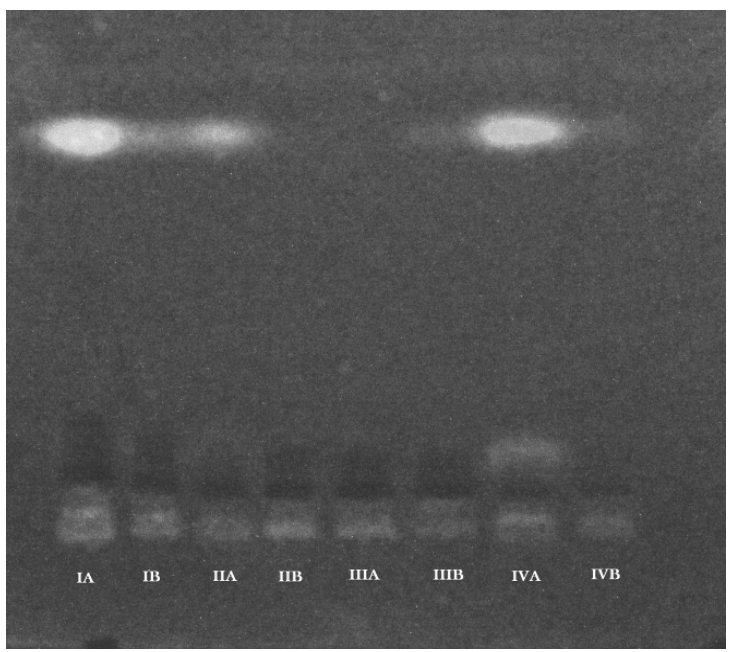

Figure 2. TLC plates of extracts of flowers of T. tenuifolia (I), T. patula (II), T. erecta (III) and T. licidum (IV)

TLC-plate - Sorbphil silica plate; mobile phase: n-hexane - acetone 10:0.1 (vol./vol.); $366 \mathrm{~nm}$ elimination. $\mathrm{A}$ and $\mathrm{B}-$ methods of plant material preparation (Figure 1)

\subsection{HPLC conditions}

The HPLC experiments were performed using Agilent 1200 equipment with diode array and mass spectrometric detection. Mass spectra were recorded under the following conditions: ionization mode APCI, positive polarity, fragmentor 100B; microcolumn $(2.1 \times 150 \mathrm{~mm})$, Kromasil-100 3.5C18; mobile phase, acetonitrile/water (8 : 2 vol./volTB) mixture; eluent delivery rate, $0.150 \mathrm{~mL} / \mathrm{min}$. Chromatograms were recorded also with diode array detection, analyzed and stored using the Agilent ChemStation software.

Mobile phases were prepared of acetonitrile (HPLC-gradient grade, Panreac) and distilled water.

\section{Results and discussion}

Marigolds tissues are known to synthesize not only xanthophyll diesters but also some thiophenes - specific sulfur-containing substances of the genus with some 
promising properties [10], for example, in hairy roots four main compounds are accumulated, 5-(3-buten-1-ynyl)-2,2'-bithienyl 5-(4-hydroxy-1-butynyl)-2,2'-bithienyl (BBT), (BBTOH), 5-(4-acetoxy- 1-butynyl)-2,2'-bithienyl (BBTOAc) and 2,2':5',2"'-terthienyl $(\alpha-\mathrm{T})$, Fig.3. Meanwhile according to the literature data [10] the only $\alpha-T$ is accumulated in Tagetes species flowers. This compound has no groups able to form hydrogen bonds and should be easily separated from xanthophyll diesters in normal-mode chromatography, for example using TLC on silica plates.

It has been found experimentally that for distinct resolution of lutein derivatives spots $(\boldsymbol{L} \boldsymbol{u})$ and that of thiophenes $(\boldsymbol{T h})$ on a silica TLC-plates the eluent may be composed of $n$-hexane with small additions of polar solvent - acetone (10: $0.1 \div 0.3 \mathrm{vol} . / \mathrm{vol}$.), the sports of $\boldsymbol{L} \boldsymbol{u}$ may be detected due to yellow color while spots of $\boldsymbol{T h}$ are known to have a bluish fluorescence under UV-excitation $(354 \mathrm{~nm})$ [11]. Spots of $\boldsymbol{T} \boldsymbol{h}$ were found at the front of eluent $\left(\mathrm{R}_{\mathrm{f}} \sim 0.9\right)$ (Figure 2).
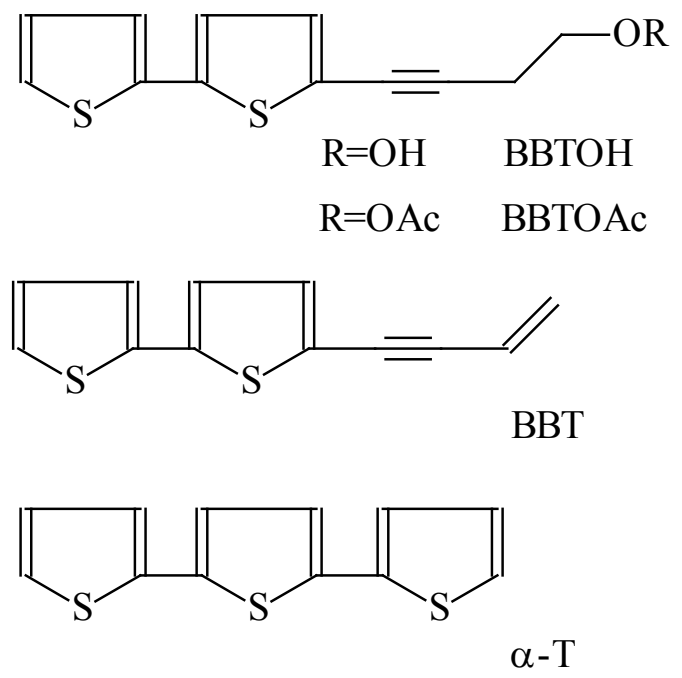

Figure 3. Structure of some Tagetes' thiophenes

The thiophene spot cannot be unequivocally attributed only to really week sorbate $\alpha$-T because another thiophene derivative (BBT) also has no polar functional groups. Thus for structure specification of the corresponding thiophene derivative HPLC investigation has been performed.

Chromatograms were recorded in isocratic elution mode in water - acetonitrile (20:80 vol./vol.) mobile phase. It has been found that thiophene composition of flowers extract is rather complicated, two or more main components were found for Tagetes species $T$. patula, T. erecta and $T$. tenuifolia (Figure 4). That of T. lucida having the same main component was of another composition, though the plant is out of industrial interest for lutein production.

Moreover, comparison of chromatograms of flowers and hairy roots (of $T$. patula) extracts has proved that $\alpha-\mathrm{T}$ is not the major thiophene component of the former extract (Figure 5). The thiophene components of marigold hairy root extracts have been investigated in some papers by HPLC and other methods including mass spectrometric detection [9] and main thiophenes components are known as those on the Figure 3.

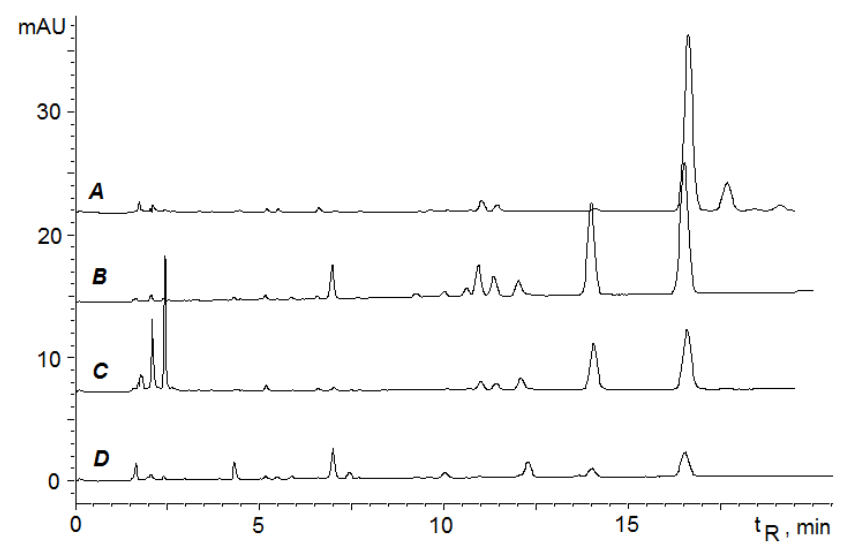

Column: $2.1 \times 150 \mathrm{~mm}$, Kromasil 100-3.5C18; mobile phase: acetonitrile water (80:20 vol./vol.); detection $350 \mathrm{~nm}$.

Figure 4. Resolution of thiophenes of flower extracts of T. lucidum (A), T. patula (B), T. tenuifolia (C) and T. erecta (D)

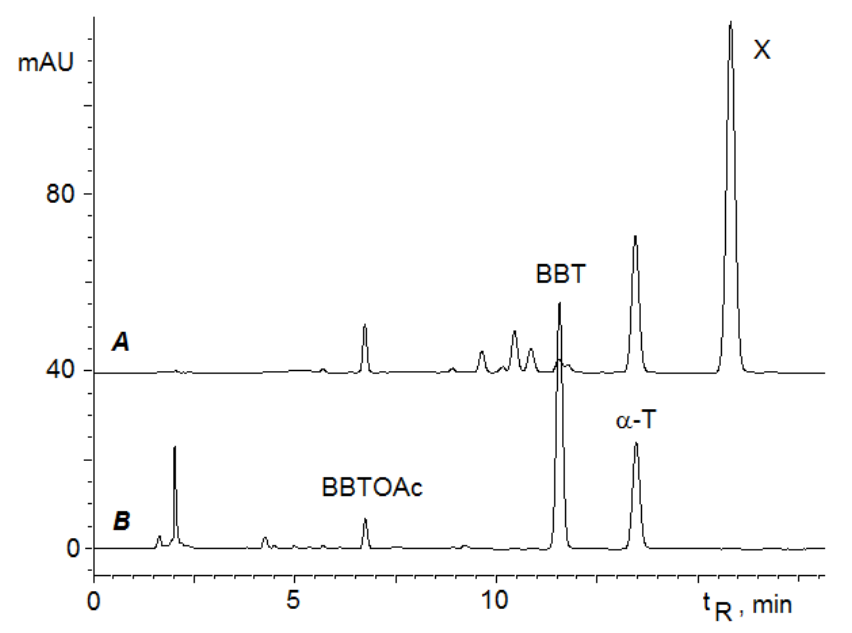

Column: $2.1 \times 150 \mathrm{~mm}$, Kromasil 100-3.5C18; mobile phase: acetonitrile water (80:20 vol./vol.); detection $350 \mathrm{~nm}$.

Figure 5. Comparisson of thiophene components of extracts of T. patula flowers (A) and hairy roots (B)

The X component on Figure 5 was absent in extracts of hairy roots, it has electronic spectra differing from that of BBT and $\alpha-T$ (Figure 6).

In the series BBT $-\alpha-\mathrm{T}-\mathrm{X}$ absorption maxima shifts bathochromically stepwise (for 7.5 and $10 \mathrm{~nm}$ ) while the electronic-vibrational character (the property of conjugated double bond systems) of the spectra seems to become more pronounced. Thus the spectra are rather characteristic, but we were not able to find electronic spectra of known thiophenes registered online by DAD in available for us literature. So for father structure elucidation were recorded mass spectra of the three compounds.

BBT (in hairy roots extracts), ${ }^{12} \mathrm{C}_{12}{ }^{1} \mathrm{H}_{8}{ }^{32} \mathrm{~S}_{2}$, has a molecular mass $216 \mathrm{Da}$, while on spectra there are signals with $\mathrm{m} / \mathrm{z}$ not only 216 (for molecular ion $\mathrm{M}+$ ) but also 217 
(for $[\mathrm{M}+\mathrm{H}]+$ ). The latter may be explained by easy protonation of the molecule having double $\mathrm{C}=\mathrm{C}$-bond. The same has been observed for $\alpha-\mathrm{T}\left({ }^{12} \mathrm{C}_{12}{ }^{1} \mathrm{H}_{6}{ }^{32} \mathrm{~S}_{3}\right)$ with $\mathrm{m} / \mathrm{z}$ $248.1(\mathrm{M}+)$ and $249.0([\mathrm{M}+\mathrm{H}]+)$ (Figure 7).

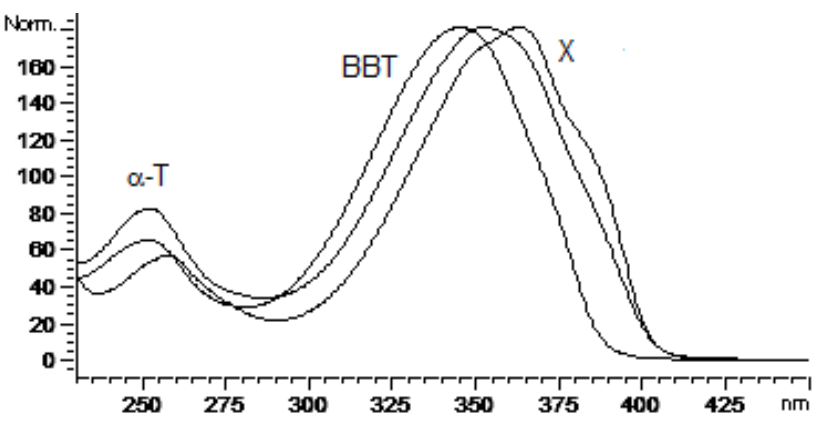

Solvent: acetonitrile - water (80:20 vol./vol.)

Figure 6. Electronic spectra of three Tagetes' thiopnenes

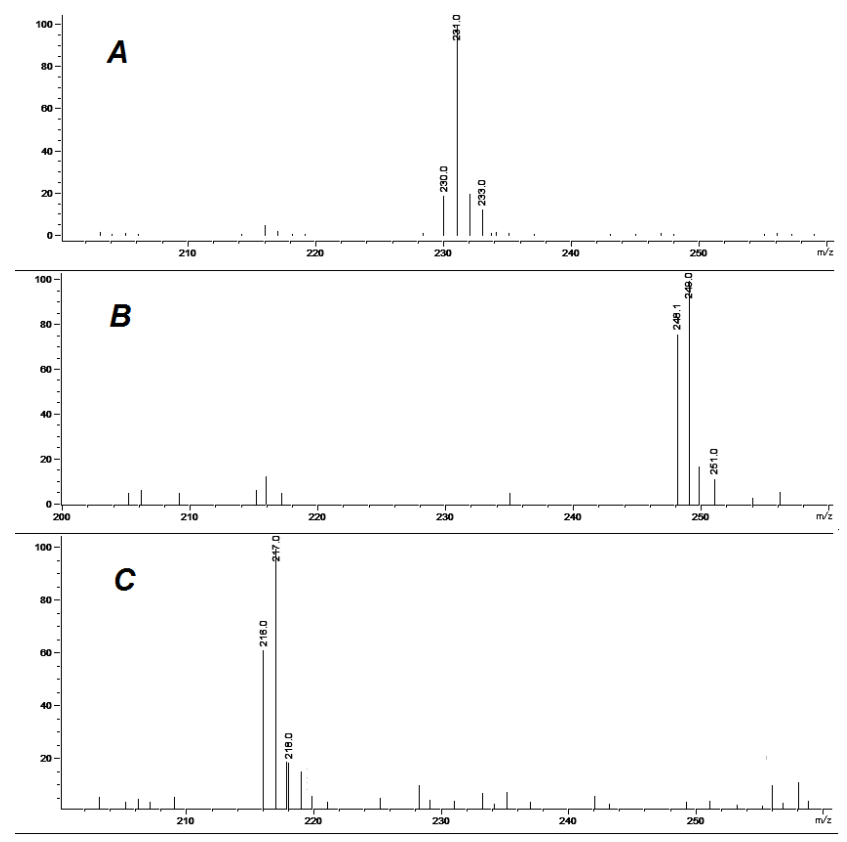

Figure 7. Mass spectrum of thiophenes X (A), $\alpha-\mathrm{T}$ (B) and BBT (C)

Signals for compound $\mathrm{X}$ have similar structure with $\mathrm{m} / \mathrm{z}$ 230 and 231, which may be attributed to $\mathrm{M}+$ and $[\mathrm{M}+\mathrm{H}]+$-ions. Thus the latter compound may have structure of BBT with additional $\mathrm{CH}_{3}$-group. Indeed, in the paper [12] two $\mathrm{C}_{13}$ bithienyls were found in $T$. erecta mutants one of them 5'-methyl-5-(but-3-en-1-ynyl)-2,2'-bithienyl (MeBBT) (Figure 8) has been proven to have the desired structure. But this compound was found only in hairy roots of mutants.

Meanwhile in the paper [9] another isomer, 5-(pent-3-en-1-ynyl)-2,2'-bithienyl (PBT), was elucidated as a major (50\%) thiophene component in flowers of $T$. patula (cv. Carmen) together with $\alpha-\mathrm{T}(34.8 \%)$ and some other compounds. The results are in full agreement with that of our investigation, thou on the basis of techniques explored in present paper it is impossible to differentiate between PBT and MeBBT. Nevertheless it is obvious that the main thiophene of flowers extract must be the substance with low affinity to silica and may be easily separated from xanthophylls diesters by sorption technology.
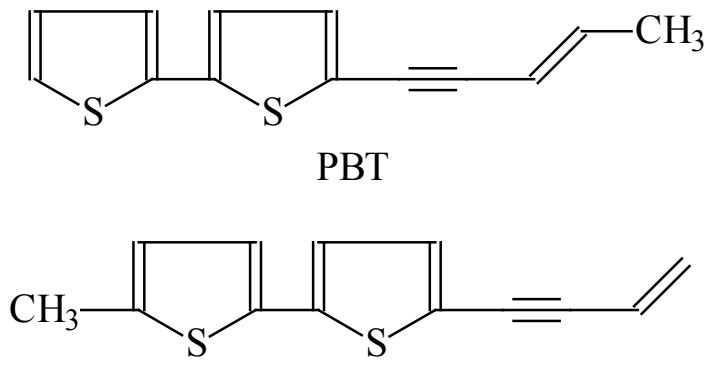

MeBBT

Figure 8. Structure of two $\mathrm{C}_{13}$ bithienyls

Meanwhile spots with bright-bluish fluorescence in case of TCL were found not for all developed plates until we made a conclusion that it is the method of initial plant material preparation that is responsible for the phenomenon. That is why we have proposed two methods of petals preparation (A and $\mathrm{B}$ ) for the further investigation.

Eight samples of extracts were prepared of fresh petals extracted in equal volumes of hexane for $T$. erecta, (cv. Gavaii), T. patula (cv. Petit orange), T. tenuifolia (unknown cv.) and T. lucida each in the two methods (A and B) and applied to the TLC-plates and then developed in a mobile phase composed of hexane : acetone $(20: 0.3 \mathrm{v} / \mathrm{v})$ mixture (Figure 2). The extracts of four Tagetes species were prepared from flowers with deep orange color (except of yellow flowers of the lonely available for us variety of $T$. lucida) and they had a closed lutein esters composition (Figure 9). The composition of lutein diesters have been proved by APCI-mass spectrometry combined with HPLC [13].

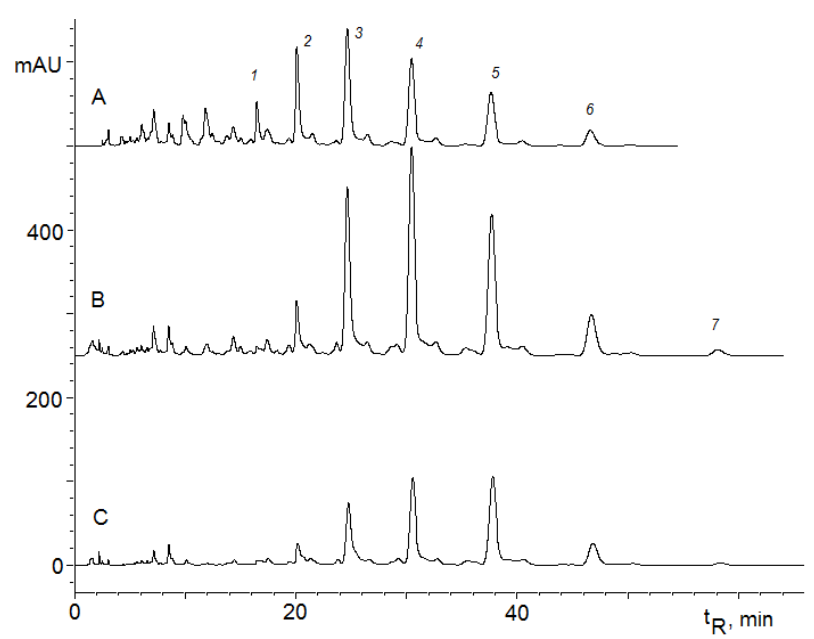

A - T. tenuifolia, B $-T$. patula, $\mathrm{C}-T$. erecta. Column: $2.1 \times 150 \mathrm{~mm}$, Kromasil 100-3.5C18; mobile phase: acetonitrile - acetone (30:70 vol./vol.); detection $445 \mathrm{~nm}$. Lutein diesters: 1 - dilaurate; 2 laurate-myristate; 3 - dimyristate; 4 - myristate-palmitate; 5 -dipalmitate; 6 - palmitate-stearate; 7 - distearate.

Figure 9. Comparisson of lutein diesters composition of extracts of some Tagetes species flowers 
Thus as may be seen directly according to fluorescence intensivity the concentration of thiophenes in petals extracts of $T$. erecta was the lowest for both types of petals preparations. The highest thiophenes concentration was found in extracts of $T$. lucida and $T$. tenuifolia florets prepared by method A. It's a favorable fact because these two latter Tagetes species are out of industrial interest for lutein manufacturing. Of the two other species (T. erecta and T. patula) extract of A-type of French marigold reveals a presence of thiophenes, while for the extracts prepared by method B for all Tagetes species thiophenes were near undetectable.

Thus it may be concluded that thiophenes known to be photosensitive are accumulated in the parts of flowers closed from sunlight by a flower's sepals. So appropriate petals preparation must be utilized to exclude the process of purification of the lutein esters from thiophenes.

If thiophenes are present in the $n$-hexane extract of xanthophyll diesters acetone must be added $(1 \mathrm{ml}$ per $100 \mathrm{ml}$ of extract) and the solution may be passed through silica column until elution of yellow fraction.

The thiophene components are not retainable in these conditions, so the first eluate may be utilized for thiophene separation. Partially cleared xanthophylls may be subsequently eluted from silica with acetone. The process may be easily controlled by TLC (Figure 10).

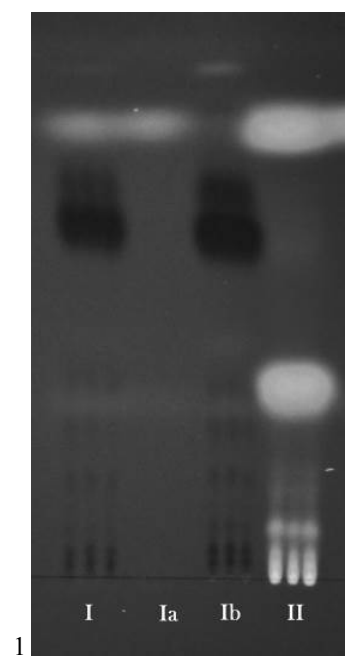

TLC-plate - Sorbphil silica plate; mobile phase: $n$-hexane - acetone 10:0.25 (vol./vol.); $366 \mathrm{~nm}$ elimination.

Figure 10. TLC control of thiophenes and xanthophyll separation by solid-phase extraction

On the Figure 10 track I belongs to initial extract of $T$. patula flowers, track Ia - to first eluate with unretained thiophenes, track $\mathrm{Ib}$ - for acetone re-extract of xanthophyll esters (before application to TLC plate re-extracted into $n$-hexane) being free from thiophenes, track II belongs to hairy root extract.

This simple method however must be explored with silica checked for absence of catalytic activity, because some commercial silica sorbents according to our experience may quickly destroy carotenoids.

\section{Conclusion}

Extracts of flowers of all Tagetes species may contain some phototoxic thiophene derivatives. $\mathrm{C}_{13}$ bithienyl was found to be a major one in all the cases under investigation instead of $\mathrm{C}_{12}$ derivatives being common for hairy roots.

It has been shown that thiophenes are accumulated mainly in the parts of flowers hidden from sunlight by a flower's sepals. Thus it is possible to exclude contamination of lutein diesters by thiophenes by a proper plant material handling.

The extracts' thiophenes under investigation have no polar groups and thus may be separated from lutein diesters by solid phase extraction. It has been shown that in case of hexane-based extracts of flowers passing through silica cartridge thiophenes were freely eluted while diesters were retained. The latter may be subsequently extracted from the cartridge by acetone. It should be taken into account that silica must be checked for absence of catalytic activity leading to xanthophyll's destruction.

TLC and HPLC methods for control of thiophene presence in extract have been developed.

\section{REFERENCES}

[1] R. Piccaglia, M. Marotti, S. Grandi, Lutein and lutein ester content in different types of Tagetes patula and T. erecta, Elsevier, Industrial Crops and Products, V.8, N.1, 45-51, 1998.

[2] V.I. Deineka, V.N. Sorokopudov, L.A. Deineka, M.Yu. Tret yakov, Flowers of marigold (Tagetes) species as a source of xanthophylls, Springer, Pharmaceutical Chemistry Journal, V.41, N.10, 540-542, 2007.

[3] V.I. Deineka, I.A. Gostyshchev, M.Yu. Tret'yakov, I.V. Indina, Carotenoids of calendula flowers petals, Belgorod, Nauchnye Vedomosti BelGU. Ser. Natural Scienses. V.104, N.9, 276-284, 2011 [Russian].

[4] G.K. Gregory, T.-S. Chen, T. Philip, Quantitative Analysis of Lutein Esters in Marigold Flowers (Tagetes erecta) by High Performance Liquid Chromatography, Wiley, Journal of Food Science, V.51. N.4, (1986) 1093-1094, 1986.

[5] D.E. Breithaupt, U. Wirt, A. Bamedi Differentiation between Lutein Monoester Regioisomers and Detection of Lutein Diesters from Marigold Flowers (Tagetes erecta L.) and Several Fruits by Liquid Chromatography-Mass Spectrometry, ACS, Journal of Agriculteral and Food Chemistry, V.50, N.1, 66-70, 2002.

[6] S. Scalia, G.W. Francis Preparative scale reversed-phase HPLC method for simultaneous separation of carotenoids and carotenoid esters, Springar, Chrornatographia. V.28, N.3, 129-137, 1989

[7] F. Khachik Patent USA 5,382,714, 1995

[8] P.E. Bowen, S.M. Herbst-Espinosa, E.A. Hussain, M. Stacewicz-Sapuntzakis Esterification does not impair lutein bioavailability in humans, ASN, Joural of Nutrition, V.132, N.12, 3668-3673, 2002. 
[9] L. Margl, A. Tei, I. Gyurján, M. Wink, GLC and GLC-MS Analysis of Thiophene Derivatives in Plants and in in vitro Cultures of Tagetes patula L. (Asteraceae). Zeitschrift für Naturforschung C, V.57c, 63-71, 2002.

[10] I. Marotti, M. Marotti, R. Piccaglia, A. Nastri, S. Grandi, G. Dinelli, Thiophene occurrence in different Tagetes species: agricultural biomasses as sources of biocidal substances, Journal of the Science of Food and Agriculture, V.90, N.7, 1210-1217, 2010.

[11] S. Hogstad., G.L. Johansen, T. Anthonsen, Possible confusion of Pyrethrins with Thiopenes in Tagetes species, Acta chemica Scandinavica. Series B, V.38, N.10, 902-904, 1984.

[12] J. J. Jacobs, R. R. Arroo, E. A. De Koning, A. J. Klunder, A. F. Croes, G. J. Wullems, Isolation and Characterization of Mutants of Thiophene, Plant physiology, V.107, N.3, 807-814, 1995

[13] M. S. Lapshova, V. I. Deineka, L. A. Deineka, I. P. Blinova, and M. Yu. Tret'yakov Identification of Xanthophylls in a Marigold Petal Extract, Pleiades Publishing, Journal of Analytical Chemistry, V.68, N.11, 1014-1019, 2013. 